\section{Association Between Increased Insulin Resistance Index HOMA-IR and COPD in a Nationally Representative Population Sample} Vasankari Tuula ${ }^{4}$, Heliövaara Markku ${ }^{5}$, Jousilahti Pekka ${ }^{5}$ and Lahtela Jorma ${ }^{6}$

${ }^{1}$ University of Tampere, School of Health Sciences, Tampere, Finland ${ }^{2}$ Department of Pulmonary Diseases, Turku University Hospital, Turku, Finland

${ }^{3}$ Department of Respiratory Medicine, Tampere University Hospital, Tampere, Finland

${ }^{4}$ Finnish Lung Health Association, Helsinki, Finland

${ }^{5}$ National Institute for Health and Welfare, Helsinki, Finland

${ }^{6}$ Department of Internal Medicine, Tampere University Hospital, Tampere, Finland

\begin{abstract}
Objective: Type 2 diabetes and impaired glucose tolerance have been associated with reduced pulmonary function. The aim of this study was to determine the potential association with the insulin resistance index (HOMA-IR index) and COPD.

Research design and methods: The data consisted of the participants $(\mathrm{N}=8028)$ of a health examination survey conducted in Finland in 2000-2001. In the present study spirometry verified COPD after exclusion of asthma and diabetes was $3.7 \%(216 / 5892)$ of the subjects.

Results: In an adjusted logistic regression model increased HOMA-IR index had a significant association with COPD (OR 1.8, $95 \% \mathrm{Cl} 1.2$ - 2.5). Adjusted linear regression model showed the association between HOMA-IR index and lack of exercise those in people with COPD $(p<0.05)$. Correlation between smoking and HOMA-IR index was significant $(p<0.01)$, but despite this in current smokers the HOMA-IR index was lower than in people with COPD who had quit or were never smokers $(p<0.001)$, there was also
\end{abstract}

*Corresponding author: University of Tampere, School of Health Sciences, Tampere, Finland; E-mail: merja.kanervisto@uta.fi

Citation: Merja K, Tarja L, Seppo S, Tuula V, Markku H, et al. (2015) As sociation Between Increased Insulin Resistance Index HOMA-IR and COPD in a Nationally Representative Population Sample. J Pulm Med Respir Res 1: 001.

Received: October 11, 2015; Accepted: November 26, 2015; Published: December 17, 2015 significant differences with the mean of BMI between those three smoking groups $(p<0.001)$.

Conclusion: In this large population based survey insulin resistance had a significant association with COPD. Further prospective studies are needed to confirm this association. Special attention should be paid to the inactivity and over weight in people with COPD.

Keywords: Chronic obstructive pulmonary disease; COPD; HOMA-IR index; Insulin resistance; Lung function

\section{Introduction}

Chronic Obstructive Pulmonary Disease (COPD) has been associated with systemic inflammation and multiple comorbidities [1].

The Homeostatic Model Assessment-Insulin Resistance (HOMA-IR) index has been developed to assess the pancreatic beta cell function. It describes this glucose-insulin homeostasis by means of a set of simple, mathematically derived nonlinear equations. The approximating equation for IR has been simplified and uses a fasting plasma sample in which glucose and plasma insulin are measured [2]. Insulin resistance is a key factor in the pathogenesis of type 2 diabetes. HOMA-IR is an independent predictor of type 2 diabetes [3]. The correlation between Cardiovascular Diseases (CVD) and insulin resistance has been known [4]. It is also noticed that type 2 diabetes [5] and insulin resistance [6] are associated with impaired lung function.

Smoking is a main causative factor for COPD. As a part of the Copenhagen City Heart Study, total of 8045 men and women aged 30 - 60 years with normal lung function were followed for 25 years in Løkke et al., study [7]. They found that the longer people smoked, the higher the risk for developing COPD was. The highest incidence for all stages of COPD was $35.5 \%$ for those who had smoked over the 25 years, while the incidence for never smokers was $7.8 \%$. They found that of continuous smokers $24.3 \%$ developed clinically significant COPD in stage 2 or worse. In addition to smoking, obesity is important risk factor of many chronic diseases. Overweight can impair respiratory function. Smoking [8] and obesity both are associated with insulin resistance, oxidative stress and increase of variety of inflammatory markers such as CRP and cytokines discharge [9]. Obesity, smoking and systemic inflammation may play role to develop metabolic syndrome [10].

Body Mass Index (BMI) is an important parameter to assess functional status of people with COPD and disease severity [11]. In Yamauchi et al., study they suggest that overweight and obese COPD patients had a lower mortality than those with low or normal weight [12].

In Hsiao FC et al., [13] study a reduction in FEV1 is proposed and useful predictor of the metabolic syndrome. We assessed the association with insulin resistance and COPD in a large nationwide population-based study. The aim of this study was to evaluate the association of the HOMA-IR index with COPD in adult (age $\geq 30$ ) Finnish population. 


\section{Material and Methods}

\section{Study design and subjects}

The study population consisted of participants of the Health 2000 survey, a comprehensive population based health examination study conducted in 2000 - 2001 in Finland. The total sample included 8028 men and women over 30 years of age, of these 7087 (89\%) responded to the interview and 6254 (79\%) went to the physical examination. A more detailed description of the participants has been reported previously [14]. Altogether 5892 subjects $(73.4 \% / 8028)$ having all needed variables, no missing values, were included in the analysis of the current study, study group consist of people with COPD $(\mathrm{N}=216)$ excluded asthma and diabetes (Figure 1).

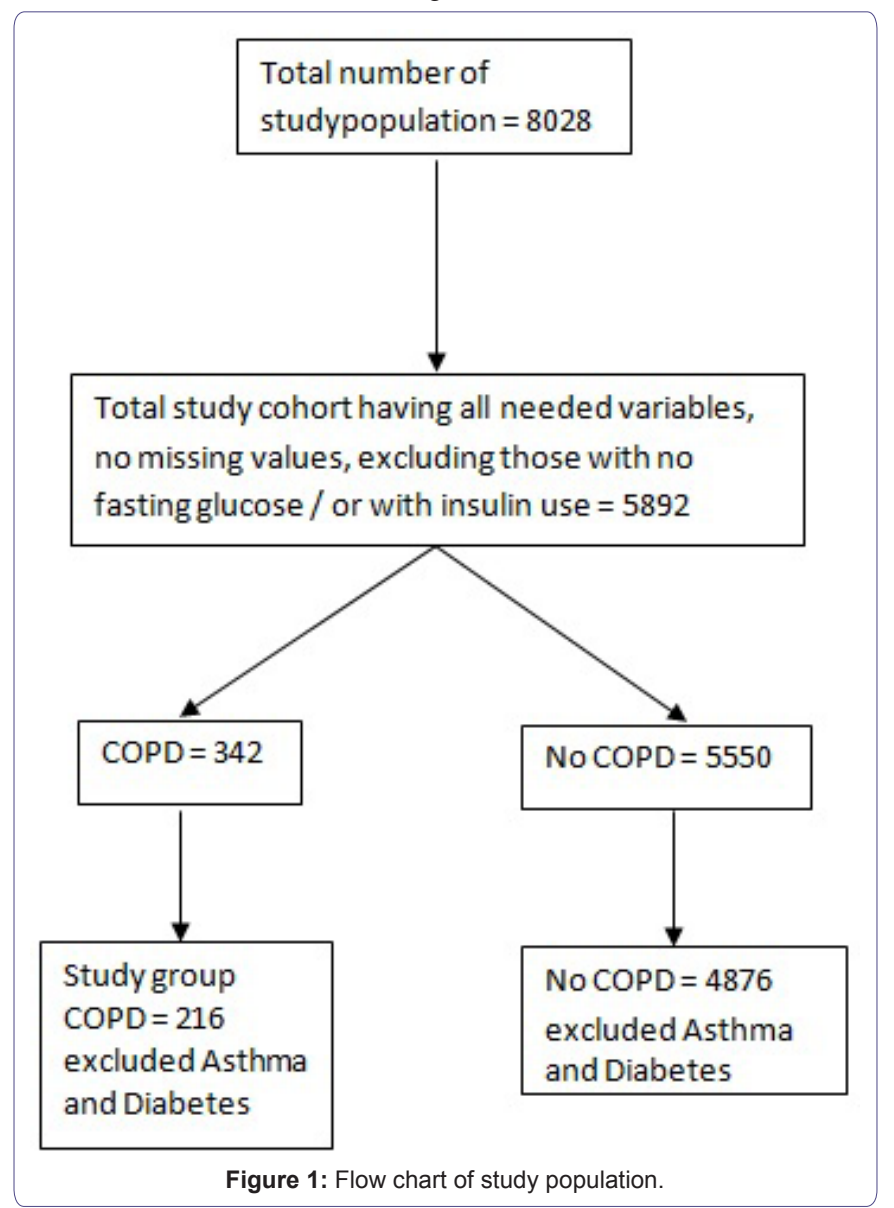

\section{Definition of COPD, insulin resistance and other study determinants}

All spirometry measurements were performed by using the Vitalograph bellow spirometers (Vitalograph Ltd. Buckingham, UK). The ratio of Forced Expiratory Volume in $1 \mathrm{~s}$ (FEV1) to Forced Vital Capacity (FVC), FEV1/FVC was calculated using the highest readings of FEV 1 and FVC from two technically valid measurements which were recorded in the BTPS values [14-16]. The definition of the COPD was based on ratio of FEV1/FVC $<70 \%$. Data on the physician diagnosed asthma and diabetes were based on self-reported questionnaire and physical examination. In the original Health 2000 survey, 355 out of 8028 study subjects had COPD, 670 had asthma and 478 had diabetes. FEV1\% of predicted as continuous variable and the Finnish reference values were used [17].
The homeostatic index of HOMA-IR was calculated as described by Matthews et al.,; glucose level $(\mathrm{mmol} / \mathrm{l}) \times$ insulin level $(\mathrm{mmol} / \mathrm{l}) / 22.5$ [2]. Low HOMA-IR values indicate high insulin sensitivity, whereas high HOMA-IR values indicate insulin resistance. The HOMA-IR index $\geq 2.5$ indicates insulin resistance [2] and this cut-off was used in this study.

Smoking was classified in four groups: daily smokers, occasionally smokers, quit smoking and never smokers. In the present study smoking was classified in three groups: current smokers, quit smoking and never smokers and then in two groups: smoking yes or no.

Blood samples for serum high sensitive C-Reactive Protein (hsCRP) determination were drawn during the clinical examination after 4 hours of fasting as described by Stenholm et al., [18].

Body Mass Index (BMI, weight/height ${ }^{2}, \mathrm{~kg} / \mathrm{m}^{2}$ ) was computed as a measure of relative weight.

Exercise capacity indicates what a person is capable to do [19]. Summated variable of exercise capacity was formed in accordance with 5 questions of mobility. A high score was considered to represent good active exercise behavior. Self-reported items concerned ability to walk for a $2 \mathrm{~km}$ or $1 / 2 \mathrm{~km}$ or climb stairs in one or more floors without resting, difficulty walking from one room to another on the same level. Questions are based on OECD recommendations (McWhinnie 1981) [16]. In addition, blood pressure values were considered, as well as cholesterol levels from the study group.

\section{Ethics statement}

The Health 2000 study was approved by the ethics committee for epidemiology and public health in the hospital district of Helsinki and Uusimaa, Finland. All participants gave their signed informed consent.

\section{Statistical methods}

The statistical analyses were done using SPSS 22.0 for Windows (SPSS ${ }^{\mathrm{TM}}$ Illinois, Chicago). Subjects' characteristics were summarized as mean (SD) for continuous variables and number of study subjects (\%) for categorical variables. Kruskall-Wallis and T-test for two independent samples $(\mathrm{p}<0.05)$ were used to determine the differences between groups. Correlation was computed among HOMA-IR index and smoking. Logistic regression (OR, 95\% CI) was used to indicate the determinants of COPD and linear regression was used to determine the relationship between HOMA-IR index and exercise.

\section{Results}

Study population consisted of a total 216 people with COPD, mostly men (63\%). Those with COPD were older than those without the disease (4876), $\mathrm{p}<0.001$. The amount of those with fasting blood glucose $\geq 7.1$ in COPD group was $2.3 \%(n=5 / 216)$ whereas $1.5 \%$ $(\mathrm{n}=72 / 4876)$ in others. Mean fs-glucose was significantly different between groups $(\mathrm{p}<0.001)$, the mean of HOMA-IR index was highest in those with COPD, as well as the s-hsCRP, but the body mass index was clearly lower $(\mathrm{p}<0.01)$ (Table 1$)$. There was no significant differences in blood pressure values or cholesterol values, systolic blood pressure in people with COPD was 133.1 (diastolic 82.3) and in those without the disease 134.1 (diastolic 81.2). There was no significant difference in blood pressure or cholesterol values. 
Citation: Merja K, Tarja L, Seppo S, Tuula V, Markku H, et al. (2015) Association Between Increased Insulin Resistance Index HOMA-IR and COPD in a Nationally Representative Population Sample. J Pulm Med Respir Res 1: 001.

- Page 3 of $5 \cdot$

\begin{tabular}{|c|c|c|}
\hline \multicolumn{1}{|c|}{ Characteristics } & COPD (N = 216) & No COPD (N = 4876) \\
\hline Gender & & \\
\hline Men & $136(63.0 \%)$ & $2236(45.9 \%)$ \\
\hline Woman & $80(37.0 \%)$ & $2640(54.1 \%)$ \\
\hline Age, mean (SD) & $67.5( \pm 13.0)$ & $50.5( \pm 13.7)$ \\
\hline BMI, mean (SD) & $25.8( \pm 4.6)$ & $26.7( \pm 4.4)$ \\
\hline Smoking & & \\
\hline Currently & $91(42.1 \%)$ & $1325(27.2 \%)$ \\
\hline Quit & $58(26.9 \%)$ & $1024(21.0 \%)$ \\
\hline Never & $67(31.0 \%)$ & $2527(51.8 \%)$ \\
\hline FP-glucose, mean (SD) & $5.6(0.6)$ & $5.4( \pm 0.6)$ \\
\hline$<7.1$ & $211(97.7 \%)$ & $4804(98.5 \%)$ \\
\hline$\geq 7.1$ & $5(2.3 \%)$ & $72(1.5 \%)$ \\
\hline HOMA-IR index, mean (SD) & $2.4( \pm 2.2)$ & $2.0( \pm 1.8)$ \\
\hline S-hsCRP mg/l, mean (SD) & $3.1( \pm 5.4)$ & $2.0( \pm 4.9)$ \\
\hline Exercise & & \\
\hline Good or adequate & $115(53.2 \%)$ & $4068(83.4 \%)$ \\
\hline Lack of exercise & $101(46.8 \%)$ & $808(16.6 \%)$ \\
\hline FEV1\% of predicted, mean (SD) & $72.5( \pm 17.9)$ & $96.5( \pm 13.2)$ \\
\hline
\end{tabular}

Table 1: Study cohort.

After adjustment for exercise, BMI, smoking, hs-CRP, gender, age in the multivariate logistic regression analysis HOMA-IR index $\geq 2.5$ was an risk factor for COPD (OR 1.8, 95\% CI 1.2 - 2.5), and remained an independent determinant for COPD (OR 1.1, 95\% CI 1.0 - 1.1) (Table 2).

\begin{tabular}{|c|c|c|c|c|c|c|}
\hline \multicolumn{7}{|c|}{ COPD } \\
\hline & \multicolumn{3}{|c|}{ Crude } & \multicolumn{3}{|c|}{ Adjusted } \\
\hline & OR & $95 \% \mathrm{Cl}$ & P-value & OR & $95 \% \mathrm{Cl}$ & P-value \\
\hline \multicolumn{7}{|l|}{ HOMA-IR index } \\
\hline$<2.5$ & 1 & & & 1 & & \\
\hline$\geq 2.5$ & 1.1 & $1.0-1.1$ & 0.003 & 1.8 & $1.2-2.5$ & 0.002 \\
\hline \multicolumn{7}{|l|}{ Exercise } \\
\hline Good or adequate & 1 & & & 1 & & \\
\hline Lack of exercise & 4.4 & $3.3-5.8$ & 0.000 & 1.5 & $1.0-2.1$ & 0.042 \\
\hline BMI & 1.0 & $0.9-1.0$ & 0.002 & 0.9 & $0.9-0.9$ & 0.000 \\
\hline \multicolumn{7}{|l|}{ Smoking } \\
\hline Never & 1 & & & 1 & & \\
\hline Quit & 2.1 & $1.5-3.1$ & 0.000 & 1.8 & $1.2-2.8$ & 0.005 \\
\hline Current & 2.6 & $1.9-3.6$ & 0.000 & 6.7 & $4.4-10.2$ & 0.000 \\
\hline S-hsCRP & 1.0 & $1.0-1.0$ & 0.003 & 1.0 & $1.0-1.0$ & 0.767 \\
\hline \multicolumn{7}{|l|}{ Gender } \\
\hline Women & 1 & & & 1 & & \\
\hline Men & 2.0 & $1.4-2.7$ & 0.000 & 1.9 & $1.4-2.6$ & 0.000 \\
\hline Age & 1.1 & $1.1-1.1$ & 0.000 & 1.1 & $1.1-1.1$ & 0.000 \\
\hline
\end{tabular}

Table 2: Logistic regression model: Association of HOMA-IR index with COPD $(\mathrm{N}=216)$ adjusted with exercise, $\mathrm{BMI}$, smoking, $\mathrm{CRP}$, gender, age

A significant regression equation was found between HOMA-IR index and lack of exercise $(F 1,214)=23,580, \mathrm{p}<0.05)$, with an $\mathrm{R}^{2}$ of 0.013. In people with COPD $1.3 \%$ of the total variation in HOMA-IR index can be explained by the linear relationship HOMA-IR index and lack of exercise, when adjusted with FEV1\% of predicted (Table 3).

\begin{tabular}{|c|c|c|}
\hline HOMA-IR index & $\boldsymbol{\beta}$ & $\mathbf{P}$ - value \\
\hline Lack of Exercise [1] & 0.146 & 0.035 \\
\hline FEV1\% of predicted & -0.007 & 0.92 \\
\hline $\mathrm{R}^{2 *}$ & 0.013 & \\
\hline
\end{tabular}

Table 3: Linear regression model: HOMA-IR index and exercise adjusted for FEV1\% of predicted (COPD, $N=216$ ).

* $=$ estimated model coefficient of determinant

The correlation between HOMA-IR index and smoking was found to be statistically significant, $\mathrm{r}=0.202, \mathrm{p}<0.01$, two - tailed. The HOMA-IR index was higher in quitters than current smokers and highest among never smokers (Figure 2), p $<0.001$. BMI among different smoking categories is in figure $2(\mathrm{p}<0.001)$.

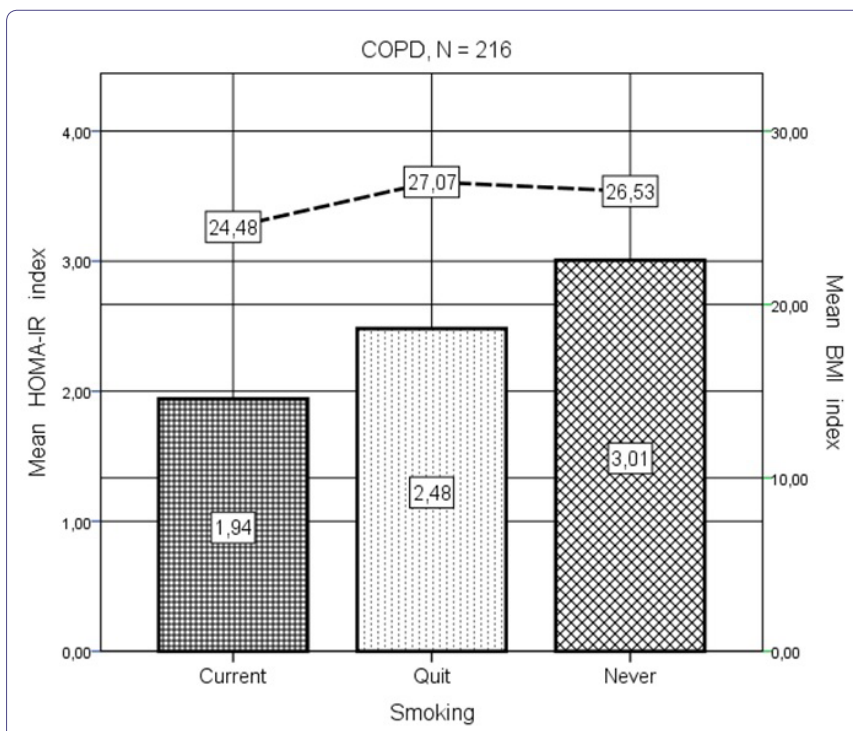

Figure 2: Mean HOMA-IR index and mean BMI index in three smoking groups, people with COPD.

\section{Discussion}

As a main finding we found that the insulin resistance (HOMA-IR index $\geq 2.5$ ) is an independent risk factor for spirometry confirmed airway obstruction and COPD. There is evidence that the insulin resistance in COPD is related to systemic inflammation [20-22]. In our study the s-hsCRP was higher in people with COPD than others. HsCRP was included to the analysis as a confounding factor of metabolic syndrome.

In our study we found a relationship between HOMA-IR index and lack of exercise among COPD subjects. It has been shown that physical inactivity increases the risk of those with COPD to develop metabolic syndrome $[22,23]$. Skeletal muscle weakness is common in people with COPD [24]. Insulin resistance may be an important mechanism in the development of skeletal muscle weakness [25]. Exercise training aims to modify skeletal muscle function to enhance exercise capacity [26] and may confer an increase in physical activity. Also the level of physical activity is most important factor in determining self - reported general health and health related quality of life in people with COPD [27,28].

Obesity is often the main cause of increased HOMA-IR index, insulin resistance [29] as well as physical inactivity, and especially abdominal obesity is associated with worsening lung function [30,31]. Some diseases as cardiovascular diseases, type 2 diabetes and the metabolic syndrome, in turn, are associated with an elevated waistline $[32,33]$. Intensive lifestyle interventions as diet and exercise can reduce 
Citation: Merja K, Tarja L, Seppo S, Tuula V, Markku H, et al. (2015) Association Between Increased Insulin Resistance Index HOMA-IR and COPD in a Nationally Representative Population Sample. J Pulm Med Respir Res 1: 001.

the incidence of type 2 diabetes of those people in risk [34]. Smoking in the study group was studied by the smoking habits: current, quit or never smokers, BMI and hsCRP was included to the analysis as a confounding factor of metabolic syndrome. COPD varies with age and smoking status [35], it rarely occurs in people under 40 years old, and COPD is more common for males than females [36], our study confirmed that. Even if there was a positive correlation between smoking and HOMA-IR index, we suggest that obese never smokers and also those who had quit smoking with severe obesity had significantly higher insulin resistance index than the current smokers.

In conclusion, our results suggest that increased HOMA-IR index $\geq 2.5$ has significant association with COPD. The strength of our study was the large study population representative of the Finnish adults and the exceptionally high participation rate. However, further longitudinal studies are needed to confirm the relationship of the association. Specific attention should be paid to inactivity and obesity in people with COPD.

\section{Acknowledgement}

The authors would like to thank Tampere Tuberculosis Foundation. This study was supported by the funding of Tampere Tuberculosis Foundation (Tampere, Finland).

\section{References}

1. Fabbri LM, Rabe KF (2007) From COPD to chronic systemic inflammatory syndrome? Lancet 370: 797-799.

2. Matthews DR, Hosker JP, Rudenski AS, Naylor BA, Treacher DF, et al. (1985) Homeostasis model assessment: insulin resistance and beta-cel function from fasting plasma glucose and insulin concentrations in man. Diabetologia 28: 412-419.

3. Bonora E, Kiechl S, Willeit J, Oberhollenzer F, Egger G, et al. (2004) Population-based incidence rates and risk factors for type 2 diabetes in white individuals: the Bruneck study. Diabetes 53: 1782-1789.

4. Kirpichnikov D, Sowers JR (2001) Diabetes mellitus and diabetes-associated vascular disease. Trends Endocrinol Metab 12: 225-230.

5. Litonjua AA, Lazarus R, Sparrow D, Demolles D, Weiss ST (2005) Lung function in type 2 diabetes: the Normative Aging Study. Respir Med 99: 15831590 .

6. Lange P, Groth S, Kastrup J, Mortensen J, Appleyard M, et al. (1989) Diabetes mellitus, plasma glucose and lung function in a cross-sectional population study. Eur Respir J 2: 14-19.

7. Løkke A, Lange $P$, Scharling H, Fabricius P, Vestbo J (2006) Developing COPD: a 25 year follow up study of the general population. Thorax 61: 935939.

8. Willi C, Bodenmann P, Ghali WA, Faris PD, Cornuz J (2007) Active smoking and the risk of type 2 diabetes: a systematic review and meta-analysis. JAMA 298: $2654-2664$

9. Poulain M, Doucet M, Major GC, Drapeau V, Sériès F, et al. (2006) The effect of obesity on chronic respiratory diseases: pathophysiology and therapeutic strategies. CMAJ 174: 1293-1299.

10. Clini E, Crisafulli E, Radaeli A, Malerba M (2013) COPD and the metabolic syndrome: an intriguing association. Intern Emerg Med 8: 283-289.

11. Celli BR, Cote CG, Marin JM, Casanova C, Montes de Oca M, et al. (2004) The body-mass index, airflow obstruction, dyspnea, and exercise capacity index in chronic obstructive pulmonary disease. N Engl J Med 350: 1005-1012.

12. Yamauchi $Y$, Hasegawa W, Yasunaga H, Sunohara M, Jo T, et al. (2014) Paradoxical association between body mass index and in-hospital mortality in elderly patients with chronic obstructive pulmonary disease in Japan. Int J Chron Obstruct Pulmon Dis 9: 1337-1346.
13. Hsiao FC, Wu CZ, Su SC, Sun MT, Hsieh CH, et al. (2010) Baseline forced expiratory volume in the first second as an independent predictor of development of the metabolic syndrome. Metabolism 59: 848-853.

14. Kanervisto $M$, Vasankari $T$, Laitinen $T$, Heliövaara $M$, Jousilahti $P$, et al. (2011) Low socioeconomic status is associated with chronic obstructive airway diseases. Respir Med 105: 1140-1146.

15. Vasankari TM, Impivaara O, Heliövaara M, Heistaro S, Liippo K, et al. (2010) No increase in the prevalence of COPD in two decades. Eur Respir $\mathrm{J} 36$ : 766-773.

16. Heistaro S (2008) Methodology Report: Health 2000 Survey. KTL-National Public Health Institute, Finland; Department of Health and Functional Capacity, Helsinki.

17. Viljanen AA, Halttunen PK, Kreus KE, Viljanen BC (1982) Spirometric studies in non-smoking, healthy adults. Scand J Clin Lab Invest Suppl 159: 5-20.

18. Stenholm S, Rantanen T, Heliövaara M, Koskinen S (2008) The mediating role of C-reactive protein and handgrip strength between obesity and walking limitation. J Am Geriatr Soc 56: 462-469.

19. Troosters T, van der Molen T, Polkey M, Rabinovich RA, Vogiatzis I, et al. (2013) Improving physical activity in COPD: towards a new paradigm. Respir Res 14: 115.

20. McKeever TM, Weston PJ, Hubbard R, Fogarty A (2005) Lung function and glucose metabolism: an analysis of data from the Third National Health and Nutrition Examination Survey. Am J Epidemiol 161: 546-556.

21. Husemoen LL, Glümer C, Lau C, Pisinger C, Mørch LS, et al. (2008) Association of obesity and insulin resistance with asthma and aeroallergen sensitization. Allergy 63: 575-582.

22. Willey KA, Singh MA (2003) Battling insulin resistance in elderly obese people with type 2 diabetes: bring on the heavy weights. Diabetes Care 26: 15801588.

23. Clini E, Crisafulli E, Radaeli A, Malerba M (2013) COPD and the metabolic syndrome: an intriguing association. Intern Emerg Med 8: 283-289.

24. Watz H, Waschki B, Kirsten A, Müller KC, Kretschmar G (2009) The metabolic syndrome in patients with chronic bronchitis and COPD: Frequency and associated consequences for systemic inflammation and physical inactivity. Chest 136: 1039-1046.

25. Mador MJ, Bozkanat E (2001) Skeletal muscle dysfunction in chronic obstructive pulmonary disease. Respir Res 2: 216-224.

26. Ohlendieck K (2012) Pathobiochemical changes in diabetic skeletal muscle as revealed by mass-spectrometry-based proteomics. J Nutr Metabol 2012: 12.

27. Maltais F, Simard AA, Simard C, Jobin J, Desgagnés P, et al. (1996) Oxidative capacity of the skeletal muscle and lactic acid kinetics during exercise in normal subjects and in patients with COPD. Am J Respir Crit Care Med 153: $288-293$.

28. Barnes PJ, Celli BR (2009) Systemic manifestations and comorbidities of COPD. Eur Respir J 33: 1165-1185.

29. Abhari FR, Andarieh MG, Farokhfar A, Ahmady S (2014) Estimating rate of insulin resistance in patients with preeclampsia using HOMA-IR index and comparison with nonpreeclampsia pregnant women. BioMed Res Int 2014: 6 .

30. Wannamethee SG, Shaper AG, Whincup PH (2005) Body fat distribution, body composition, and respiratory function in elderly men. Am J Clin Nutr 82: 996-1003.

31. Gibson GJ (2000) Obesity, respiratory function and breathlessness. Thorax 55: 41-44.

32. Ochs-Balcom HM, Grant BJ, Muti P, Sempos CT, Freudenheim JL, et al. (2006) Pulmonary function and abdominal adiposity in the general population. Chest 129: 853-862. 
Citation: Merja K, Tarja L, Seppo S, Tuula V, Markku H, et al. (2015) Association Between Increased Insulin Resistance Index HOMA-IR and COPD in a Nationally Representative Population Sample. J Pulm Med Respir Res 1: 001.

- Page 5 of $5 \cdot$

33. Leone N, Courbon D, Thomas F, Bean K, Jégo B, et al. (2009) Lung function impairment and metabolic syndrome: the critical role of abdominal obesity. Am J Respir Crit Care Med 179: 509-516.

34. Chen CN, Chuang LM, Wu YT (2008) Clinical measures of physical fitness predict insulin resistance in people at risk for diabetes. Phys Ther 88 : 13551364
35. Hurd S (2000) The impact of COPD on lung health worldwide: epidemiology and incidence. Chest 117: 1-4.

36. Arne M, Lundin F, Boman G, Janson C, Janson S, et al. (2011) Factors associated with good self-rated health and quality of life in subjects with self-reported COPD. Int J Chron Obstruct Pulmon Dis 6: 511-519. 